issn: $1808-799 \mathrm{X}$

ano 4 - número 4 - 2006

\title{
SOBRE(O)VIVER DE CRIANÇAS E ADOLESCENTES: UMA REFLEXÃO ACERCA DO MÉTODO DE PESQUISA
}

\author{
Ana Aparecida Arguelho Souza[i] \\ Elcia Esnarriaga de Arruda[ii] \\ Sonia Maria Pereira[iii] \\ Maria de Fátima Evangelista Mendonça Lima *
}

\begin{abstract}
... Para algo mais chamamos a vossa atenção. Procuramos cercar nossas reflexões dos maiores cuidados, não apenas para que fossem verdadeiras, mas também para que não se apresentassem de maneira incômoda e árida ao espírito dos homens, usualmente tão atulhado de múltiplas formas de fantasia. Em contrapartida, solicitamos dos homens, sobretudo em se tratando de uma tão grandiosa restauração do saber e da ciência, que todo aquele que dispuser a formar ou emitir opiniões a respeito

do nosso trabalho, quer partindo de seus próprios recursos, da turba de autoridades, quer por meio demonstrações (que adquiriram agora a força das leis civis), não se disponha a fazê-lo de passagem e de maneira leviana. Mas que antes se inteire bem do nosso tema; a seguir, procure acompanhar tudo o que descrevemos e tudo a que recorremos; procure habituar-se à complexidade das coisas, tal como é revelada pela experiência; procure, enfim, eliminar com serenidade e paciência os hábitos pervertidos,

já profundamente arraigados na mente. Aí então, tendo começado o pleno domínio de si mesmo, querendo, procure fazer uso de seu próprio juízo.
\end{abstract}

Francis Bacon

\section{Introdução}

Em 1996, a Secretaria Municipal da Criança e do Adolescente solicitou à Universidade Federal de Mato Grosso do Sul uma pesquisa sobre o atendimento à criança e o adolescente em Campo Grande/MS. Atendendo ao desafio, produzimos[iv], à época, um relatório que foi encaminhado à Secretaria solicitante. Desde então, parte do relatório, que trata do método, tem sido veiculada entre alunos e professores por um interesse que o Método de investigação suscitou entre pesquisadores. Estimuladas por essas solicitações, produzimos o presente artigo, que apresenta os pressupostos sobre o método que norteou aquela pesquisa.

\section{A construção do objeto no interior de um aporte teórico}

Assim, todos, juntos, continuavam a sua vida cotidiana, cada um a seu modo, com ou sem 
reflexão; tudo parecia seguir o seu rumo habitual, como em situações extremas, nas quais tudo está em jogo, e a vida continua como se nada acontecesse.

Goethe

Desde o momento em que assumimos a realização da pesquisa que deu origem a este artigo, anunciamos a intenção de transpormos os limites de um levantamento de dados puramente quantitativos, para buscarmos, no confronto entre o movimento de uma determinada sociedade e a teoria nela produzida, os dados que informaram nosso objeto, qual seja: a natureza do atendimento realizado, ou não, pelas instituições que têm definido as políticas e desenvolvido os programas de atendimento às crianças e adolescentes, em Campo Grande - MS. Essa intenção sustenta-se no entendimento de que a primeira etapa de qualquer tipo de investigação, que pretenda ter caráter científico, demanda essa forma de análise sob pena de, em não captando as raízes do objeto investigado, propor soluções superficiais e paliativas.

Essa postura exigiu, de nossa parte, a explicitação de algumas categorias fundantes, que informaram o relatório inicial e que julgamos necessário manter neste artigo, por fidelidade e rigor de método.

A primeira é a própria concepção do que seja pesquisa. Muitos manuais de metodologia científica definem o termo com a superficialidade própria do pragmatismo de nossa época, entendendo pesquisa como simples indagação empírica, em que a confirmação de dados observáveis e quantificáveis é elemento suficiente ao entendimento de um determinado objeto.

Para contrapor essa perspectiva, própria do método positivista, é necessário recorrer ao confronto de duas categorias, cuja explicitação já provoca uma diferença no entendimento acerca da natureza do objeto investigado. Tais categorias são o empírico e o concreto, usualmente, tomadas uma pela outra.

Vejamos: o empírico é o elemento efetivamente observável, a realidade vista a olho nu. Por exemplo, se tomarmos como objeto de análise o conjunto das crianças que fazem ponto ao longo da Av. Afonso Pena, no horário comercial, com a finalidade de tomar conta dos carros que estacionam nos canteiros, a empiricidade do objeto está dada pela possibilidade de quantificarmos essas crianças, por um determinado tempo, detectarmos o número de contatos feitos com os motoristas, o total de dinheiro que arrecadam ao dia, o que lhes rende ao mês tal tarefa, etc. A partir desses dados e de quantos mais pudermos observar e quantificar, podemos propor ações e políticas para tentar tirá-los da rua. Podemos ir ainda mais longe: conversar com esses meninos perguntando-lhes o que fazem com o dinheiro, acompanhar seu percurso até o bairro onde moram, constatando o nível de qualidade de sua habitação ou, até mesmo, confirmando hipóteses de que seus pais os abandonaram, de que sua habitação é a rua, de que usam o dinheiro para aquisição de drogas, etc. Com esses dados poderemos inclusive construir a ilusão de que saímos do puramente quantitativo, rumo a uma abordagem qualitativa da realidade, como 
querem as chamadas abordagens qualitativas de pesquisa. Entretanto, continuaremos a enxergá-la nos limites do empirismo, pois que tais constatações não permitem identificar os móveis determinantes dessa qualidade materializada.

O que dá concretude a esse mesmo objeto? O que o torna concreto? É o seu caráter histórico, isto é, o fato de esta situação singular conter em si elementos universais e, portanto, não observáveis, impossíveis de serem apreendidos, senão por meio da teoria. Não de qualquer teoria, mas daquelas que permitem a compreensão da historicidade do objeto, teorias que ao serem formuladas conseguiram apreender o movimento do conjunto dos homens na produção da vida, suas contradições, seus embates, ao longo dos tempos. Essas teorias revelam o movimento dos homens na sua caminhada, tal como ela veio se configurando, de modo a criar a situação referida, isto é, meninos na rua cuidando carros. A dinâmica da sociedade, que engendrou a existência material de crianças de rua, é o que confere concretude ao objeto. De modo que se tem aí um mesmo objeto, visto de forma distinta: pelo olhar do empirismo e pelo olhar da concretude histórica. É Lukács que aponta com precisão as categorias que permitem uma leitura mais radical acerca da concretude. Diz o autor que, embora a economia política nos seus primórdios tenha começado com a análise empírica da totalidade social (como em Smith e Locke, por exemplo), ao longo do seu desenvolvimento enquanto ciência, acaba por elaborar, por meio da abstração e da análise, algumas relações determinadas (mediações). São essas mediações que permitem afastar da análise qualquer empirismo, na medida em que acabam por demonstrar o caráter de concretude da sociedade: "O concreto é concreto porque é soma de muitas determinações, isto é, a unidade do múltiplo” (Lukács:1978, p.74/75).

Isso nos impõe uma redefinição do conceito de ciência. Visto que as questões com as quais se depara toda a investigação têm uma concretude histórica, a ciência hoje não pode ser tomada nos patamares do positivismo, onde só é científico o que pode ser observado, experimentado, quantificado. A ciência positivista é uma produção humana necessária para referendar os valores e os ideais de uma determinada época. Formulada por Auguste Comte, na segunda metade do século XIX, tem como núcleo a idéia de que a sociedade só pode ser reorganizada por meio de uma completa reforma intelectual do homem. Sua base filosófica pode ser sintetizada na Lei dos Três Estados que defende a idéia de que o espírito humano e as ciências evoluem por estágios: primeiro estado, o teológico, a seguir, o metafísico e, por último, o positivo. Essa concepção de ciência evolucionista informou não só a pesquisa, mas toda a cultura de uma época, até o início do século $X X$, após o que, gradativamente, dividiu espaço com as teorias de base fenomenológica e marxista, e seus desdobramentos.

A partir de uma perspectiva histórica pode-se compreender as diferentes formas de produção do conhecimento, inclusive a pleiteada por Comte. Quando se analisa um determinado objeto levando em conta a sua concretude, a cientificidade da análise reside justamente na sua capacidade de apreender, na teia das relações sociais, o próprio 
movimento da história que determinou e assim configurou aquele objeto.

Nesse sentido, já definiu MARX em A Ideologia Alemã: "Conhecemos apenas uma única ciência, a ciência da história".[v] De modo que a única categoria capaz de conferir cientificidade à análise e, portanto, capaz de validar os resultados de uma pesquisa é a história. O modo de conceber uma natureza histórica para todas as coisas, o que pressupõe movimento, apóia-se no pressuposto marxiano de que toda mudança ocorre por transformações de caráter qualitativo. A concepção de história de que aqui se trata afastase das teorias evolucionistas que informaram o modo de pensar da modernidade.

O desenvolvimento, em Marx, difere de evolução, exatamente naquilo que o trabalho enquanto categoria fundante da espécie humana permite: transformações de ordem qualitativa. Confundir evolucionismo com transformação é um equívoco recorrente nas pretensas críticas à concepção de história formulada por Marx. O evolucionismo pressupõe um continum, um progresso, um melhoramento da mesma coisa. Quando, porém, ocorrem transformações de ordem qualitativa, o que era não é mais. Ocupou seu lugar algo de qualidade nova, isto é, de natureza nova. O próprio homem é um ser qualitativamente diferente das demais espécies biológicas, no porte físico, na questão da linguagem, da consciência, é um ser social. (SOUZA, 2001, p. 37)

Este é o aporte metodológico que foi utilizado na pesquisa em questão para a elucidação do objeto. Essa teoria permitiu aventar a seguinte hipótese que, posteriormente, foi confirmada pelos dados: a natureza do atendimento realizado pelos órgãos públicos à criança e ao adolescente decorre de uma necessidade inerente ao modo como a sociedade capitalista resolve as tensões sociais criadas por outra necessidade, a de garantir o curso da acumulação do capital financeiro nos patamares da concentração monopólica, sem provocar o colapso social que poderia ser gerado pelo caráter excludente que marca os setores produtivos.

Tratar da história na perspectiva do marxismo não é uma tarefa de pequena monta. Impõe, já de início, a intenção de irmos buscar a sua compreensão, não nos manuais de historiografia oficial, nos contadores de história, mas na leitura da teoria produzida pelos homens que, vivendo em determinadas épocas e lugares, registraram com muita clareza as relações sociais que os caracterizavam.

Ao realizar tais leituras, a constatação é a de que, no interior de cada forma social, os homens produzem a vida de maneira diferenciada. E mais, de que a passagem de uma para outra forma social realiza-se pelo confronto entre forças sociais antagônicas e contraditórias. Poderíamos aqui fazer uma exposição acerca das peculiaridades das formas sociais escravistas, isto é, das sociedades grega e romana, do que lhes confere unidade e de como esta última constituiu-se, ergueu-se e, entrando em crise, decompôsse, dando lugar à forma social feudal. No entanto, a natureza daquela pesquisa não exigiu uma discussão de tal monta, o que poderia, inclusive, conduzir ao risco de descaracterização do objeto. A menção é feita apenas para reafirmar a historicidade da 
trajetória humana, numa perspectiva diferente da historiográfica oficial. A simples apresentação de fatos cronologicamente distribuídos não garante a apreensão do objeto em sua totalidade. Interessa-nos, pelo contrário, apreender os fundamentos históricos desta sociedade, a que chamamos sociedade burguesa, sociedade moderna ou capitalismo, na perspectiva da luta e da apreensão das contradições. Compreender esses fundamentos impõe, finalmente, a discussão de mais uma categoria: a necessidade.

Usualmente, para a feitura de uma pesquisa, os manuais de metodologia científica orientam o pesquisador na formulação de um problema para o qual, através da investigação, se obtenha um resultado que permita, quando não apontar caminhos para a superação do mesmo, pelo menos que ele se torne mais compreensível.

Não entendemos que no trato de um objeto devamos lidar com um problema em si ou problematizá-lo porque, na ótica da história, as questões que se colocam na sociedade e se constituem objetos de investigação não são problemas, mas representam a forma mesma de se responder às necessidades sociais, a cada época; e se aparecem de uma determinada forma que parece problemática, é porque a sociedade em si não consegue, ou não quer, respondê-las de outra forma. Cabe, então investigar, não problemas, mas quais necessidades impostas por determinada ordem social engendraram esta ou aquela situação.

Tomemos a mesma questão: meninos de rua cuidando de carros. Imaginar, na sociedade atual, a possibilidade de inexistir tal situação é desconsiderar todo o movimento dos homens nas suas relações sociais, conduzindo a história de uma forma tal que num dado momento a possibilidade de sobrevivência de suas crianças e adolescentes reside nos trocados que recolhem dos motoristas, impelidos pela solidariedade ou pelo medo.

Isto significa que as necessidades são produzidas pelos homens, socialmente, bem como as respostas para elas e, como toda a produção humana, servem a um tempo e depois perecem: necessidades e respostas.

A existência de um contingente cada vez mais ampliado de crianças nas ruas, sem raízes, sem destino, é a expressão necessária de uma forma de organização dos homens, cuja origem está no modo como o trabalho estruturou-se na sociedade moderna. E a tarefa de tomar conta dos carros é a forma de resposta gerada pela própria sociedade, para atender a essa necessidade. As diferentes modalidades de atendimento, realizadas pelo Estado e pelo conjunto da sociedade, e que foram analisadas na pesquisa são, igualmente, formas de responder às necessidades colocadas pela história.

O entendimento científico dessa questão nos remete à investigação das raízes da sociedade burguesa, cujo próprio surgimento respondeu a necessidades sociais de uma determinada época. O conjunto da teoria e da arte produzido pelos burgueses nos séculos $\mathrm{XVI}, \mathrm{XVII}$ e até XVIII revela que quando a relação social estabelecida no interior do feudalismo não permitiu mais a manutenção da vida do conjunto de toda a sociedade, os 
homens passaram a procurar respostas fora daquela relação.

Materialmente, essa resposta expressou-se, primeiro no trabalho das manufaturas, depois no da grande indústria, os quais possibilitaram a absorção de grandes contingentes humanos em seu interior, permitindo assim a continuidade de sobrevivência da espécie humana. Esse trabalho só foi viável dentro de uma nova relação social diferente daquela estabelecida entre o servo e o senhor feudal.

No pensamento de LOCKE[vi], vamos encontrar explícita essa nova relação que é fundada na troca de força de trabalho por salário. Os lemas da bandeira iluminista igualdade e liberdade não são meras palavras. Eles encontraram lastro na igualdade real conferida aos homens pelo fato de todos, no interior da relação burguesa possuírem uma propriedade inalienável em seu próprio corpo: sua força de trabalho. E pela liberdade de cada homem de vender ou comprar essa força de trabalho, empregando-a na produção. Nisso residem os fundamentos históricos da igualdade e liberdade burguesas. Foi, portanto, no interior do trabalho industrial, cuja produção de mercadorias só pode ser realizada através da troca - força de trabalho x salário - que a sociedade pôde erigir-se até chegar nos patamares atuais e possibilitar a sobrevivência e a continuidade da espécie humana. De modo que, enquanto sobrevive tal relação, realiza-se a produção da vida dentro dos patamares da sociedade burguesa. Por realizar-se a produção da vida quer entender-se aqui a possibilidade de absorção de toda a sociedade em modalidades de trabalho nas quais aquela troca se realiza.

De modo que, concretamente, essa relação materializou-se, inicialmente, no interior das manufaturas onde o processo de trabalho se diferia radicalmente dos processos artesanais, próprios da sociedade feudal. Nestes, um mesmo trabalhador realizava, sozinho, todas as operações, na produção de um determinado objeto tendo, portanto, um pleno domínio do processo global do trabalho desenvolvido. A forma artesanal de produzir objetos dificultava a produção em larga escala e nem era seu propósito[vii]. E, normalmente, o mesmo artesão que produzia, comercializava o produto do seu trabalho. Essa modalidade de trabalho, bem como aquela realizada pelo servo, que tirava da terra o seu sustento e o do senhor a quem servia, constituem as formas típicas de trabalho da sociedade feudal, e no interior dessas relações, era impossível falar em troca de trabalho por salário. Já na manufatura, em razão do sistema de cooperação, primeira forma de trabalho tipicamente burguesa, cada operação do processo de produção da mercadoria era realizada por um determinado operário em troca de salário, cujo recebimento lhe permitia a reprodução da vida.

O trabalho manufatureiro e o industrial demandaram a produção de ciência e tecnologia em níveis cada vez mais elevados em razão da produtividade e competitividade de mercado. A realidade da indústria, que com sua tecnologia incipiente permitiu a absorção de grandes contingentes de trabalhadores no seu interior, começa a mudar sua face na medida em que os instrumentos de trabalho vão se acoplando em máquinas, cuja força 
motriz não está mais na esfera humana. Isto não só retira do trabalhador o domínio sobre a produção, como também o transforma em peça acessória nos processos produtivos, já que as operações antes realizadas por ele, agora estão objetivadas nas máquinas. Esse fenômeno da objetivação do trabalho através da incorporação de ciência e tecnologia na produção, que permite a automação dos processos produtivos, constituiu a resposta que os homens formularam historicamente para viabilizar as condições materiais da vida, nos patamares atuais. Entretanto, a história está a cobrar o seu preço aos homens que julgaram assim satisfazer todas as necessidades humanas, nos termos da sociedade burguesa. Se, por um lado, a produção de ciência e tecnologia nos permitiu viver a vida de modo extremamente confortável, tanto em termos de habitação, saúde, lazer, transporte, facilidades domésticas etc., por outro, essa mesma objetivação gerou um quantitativo de desempregados que, no momento atual, ameaça a ordem social em seus fundamentos.

Essa situação provocada pela objetivação do trabalho tem início no século XIX, na Europa. A indústria que, em seus primórdios, absorveu até o trabalho infantil, começa por expulsar das fábricas, primeiro as crianças, quando as máquinas ocupam o seu lugar na produção. Até então, não se falava em meninos de rua. O que havia eram meninos na fábrica. Hoje, não só assistimos a crescente ampliação do contingente de meninos de rua como vemos desfilar diante de nossos olhos atônitos, famílias de rua, gerações de rua.

É claro que existem causas de ordem conjuntural que interferem na produção dessa situação, mas estas empalidecem diante da causa estrutural que determina a ampliação desse contingente cada vez mais volumoso de pessoas fora da produção. Como causa estrutural tem-se o movimento histórico da produção capitalista, no seu anseio de elevar o nível de produtividade e, em conseqüência, o lucro de suas indústrias e os recursos científicos e tecnológicos de que dispõem hoje para alcançar tal intento.

Os jornais têm nos trazido, diariamente, informações acerca do corte de trabalhadores na produção. Muito mais do que no Brasil, é nos países de tecnologia mais avançada como Alemanha, Japão, Estados Unidos que o fantasma da automação ameaça a sobrevivência de grandes parcelas da população,[viii] ao mesmo tempo em que inviabiliza a relação de troca entre força de trabalho e salário.

A gradativa extinção dessa relação provocada pela necessidade de manutenção ou ampliação do lucro das empresas, ao mesmo tempo em que responde a tal necessidade, cria outras:

1. Como organizar a produção capitalista para a geração do lucro, mantendo em seu interior um quantitativo mínimo de trabalhadores assalariados?

A resposta vem sendo dada pelos setores empresariais e pelas grandes indústrias. Essa resposta se apresenta no interior das indústrias como a superação da produção seriada típica dos processos tayloristas e fordistas de trabalho e sua substituição pelo toyotismo, cuja característica básica reside na capacidade de um mesmo trabalhador operar 
simultaneamente com várias máquinas. O trabalho passa então a ser "realizado em equipe, rompendo-se com o caráter parcelar típico do fordismo"[ix]. Isso "flexibiliza" o aparato produtivo, bem como toda a organização do trabalho e, explicitado de um ponto de vista histórico, significa apenas a intensificação da exploração do trabalhador, uma vez que um único indivíduo passa a desempenhar as tarefas de vários outros, o que permite a expulsão de um número cada vez maior de trabalhadores dos processos de produção. Logo, não é difícil concluir que tal resposta, baseada no interior do mundo do trabalho, se por um lado responde à necessidade de obtenção do lucro, por outro, estimula o esfacelamento da relação fundamental que ergueu a sociedade burguesa: trabalho $x$ salário.

2. Como produzir condições de sobrevivência aos seus membros (quase a totalidade), que não conseguem mais realizar a troca de seu trabalho por salário?

Aqui, a resposta vem sendo dada através de ações desenvolvidas: 1) pelo Estado, materializado nos ministérios e secretarias públicas e pelos governos em gestão; 2) pelo conjunto da sociedade, materializado pelas ONGs (organizações não governamentais), conselhos estaduais, municipais, instituições filantrópicas, etc.

E aqui chegamos também ao âmago de nossa questão: visto que a população infantojuvenil que é objeto mais enfático das preocupações gerais, e mais imediatamente alvo das políticas de atendimento, é aquela de jovens e crianças despossuídas, que fazem da rua sua morada e, mais de perto, "ameaçam" a ordem social e, mais de perto, sensibilizam as emoções e, mais de perto, provocam um sentimento de urgência em resolver o problema e, visto ainda, que a existência dessas crianças e adolescentes de ruas é resultado de uma relação social (Trabalho $X$ Salário) que, no seu processo de extinção irá ampliar, gradativa e inevitavelmente esse contingente, indagamos: qual a resposta possível ou a mais adequada a essa situação social, gerada pela necessidade do lucro desenfreado? A resposta exige uma compreensão dos efeitos que a falência da relação fundamental trabalho x salário - causa no conjunto de toda a sociedade, incluso aqui o Estado. Nesse sentido é que outras categorias de análise, se tornam fundamentais, vindo somar à de necessidade: são as de luta e movimento.

A própria história tem mostrado que, no tempo que antecede o surgimento de uma nova sociedade, tudo se torna diluído, sem uma forma precisa: as instituições que representam a velha sociedade, os valores que a sustentam, as leis que a regem. Isso acontece porque as instituições, as leis, os valores, qualquer coisa que seja, são construções humanas e, portanto, sociais. E quando uma sociedade entra em crise permanente, porque a relação fundamental que a erigiu e sustentou entrou em colapso, todas as suas construções perdem o vigor. E olhando para a história, único olhar que nos permite enxergar a realidade em movimento e, portanto, livre dos dogmas e, por isso mesmo, de forma científica, podemos detectar na sociedade atual, todos os indícios de sua senilidade. 
Somente a busca da teoria, porém, pode confirmar esses indícios. Aqui foi a leitura dos clássicos $[\mathrm{x}]$ que permitiu, com isenção, captar o movimento da história, pelo relato dos homens que a viveram. Por essas leituras, confirmam-se dois supostos básicos: 1) Podemos observar semelhanças entre o momento de falência da relação de servidão, própria do feudalismo, e este momento da sociedade contemporânea: grandes contingentes de desocupados, sem uma relação de trabalho que lhes permita a sobrevivência[xi], um novo jeito de trabalhar instaurando-se[xii], o monopólio de toda a sociedade na defesa de suas instituições, relações e valores em colapso[xiii], os limites do conhecimento produzido no interior das relações feudais, para uma compreensão da nova sociedade em curso[xiv]. 2) A sociedade burguesa só conseguiu firmar sua relação fundamental e erguer-se nos patamares atuais em decorrência de sua luta feroz enquanto nova força histórica emergente, com as forças feudais no seu movimento de conservação da história. Com as manufaturas em uma mão e a ciência experimental em outra, a burguesia enfrentou até à morte: os monopólios das corporações de ofício, instituições feudais que impediam o livre curso da produção; a Inquisição, a mais violenta arma, acionada pela Igreja Feudal, que arrastou às fogueiras todos os que se atreveram a pensar e construir instrumentos para a instauração da sociedade burguesa; e o poder político de uma aristocracia improdutiva e feroz na defesa de seus privilégios.

Uma vez instaurada, após séculos de luta, a sociedade burguesa organiza seu Estado, sob a égide do qual, por muito tempo avançou. Na leitura de Locke encontram-se os elementos necessários à compreensão do Estado burguês, cujo surgimento decorreu exatamente da necessidade de organizar a sociedade em defesa da relação de propriedade[xv]. Nesse momento, estado e sociedade se confundem porque seus interesses são os mesmos. Existe uma nova sociedade em curso que outorga ao Estado o gerenciamento do bem comum. A dinâmica de cobrar impostos à produção e, com eles, promover o atendimento às necessidades sociais é a tônica do Estado burguês, o que permitiu inclusive, por um determinado período, a possibilidade de um Estado do Bem-Estar Social, até o momento em que a concentração, acumulação e centralização de capitais, de um lado, e a avalanche de novas tecnologias, reorganizando toda a produção, de outro, inviabilizaram o encontro entre as duas forças básicas da sociedade burguesa: capital e trabalhadores. Estes, afastados da produção, sem possibilidade de gerar riqueza social, mas sempre com necessidade de sobrevivência, direcionam o Estado para além de sua função de provedor do bem-estar social. A partir de um dado momento, esse Estado se depara com um contingente tão volumoso de pessoas fora da produção que passa a não conseguir atender a todas as necessidades sociais, limitando-se a uma função predominante: realocar os excedentes da produção[xvi]. E até esse papel, tem cumprido a duras penas. A crise mundial da economia burguesa, somada à corrupção e ao clientelismo, aos quais o Estado tem sempre que recorrer para manter sua sobrevida enquanto instituição em colapso, não lhe permite um desempenho melhor do que aquele que vem realizando. Ao criar escolas, creches, ao inchar instituições públicas com subempregos, ao formular 
políticas de atendimento à população, atende apenas no limite de suas possibilidades para garantir condições mínimas de sobrevivência e "equilíbrio social". Tal é a tarefa que, contemporaneamente, o grande capital internacional outorga ao Estado.

De modo que a sociedade burguesa tem hoje o Estado possível, as instituições possíveis, os valores possíveis. Uma sociedade claramente mergulhada na barbárie não poderia conter no seu interior, algo infenso à barbárie. É, portanto, dentro desses limites e possibilidades que realizamos o tratamento dos dados coletados naquela pesquisa. Um momento assim, no qual claramente há indícios de que uma sociedade está no seu limiar, possibilitando o surgimento de uma outra, porque todas as suas relações entraram em colapso, nos traz, amalgamados na mesma realidade, elementos do velho e do novo; e delineia, nitidamente, um movimento compacto de forças sociais conservadoras, que no ímpeto de salvar as relações burguesas, promulgam leis, decretos, definem e redefinem políticas, desencadeiam ações, tudo numa tentativa desesperada de ajustar, com todo esse aparato, o movimento da vida dos homens no interior de relações falidas. $E$ a razão porque, apesar de todos os esforços do Estado e da sociedade não há o ajuste, é que novas forças sociais estão em curso, apontando para uma nova relação social, da qual não temos ainda o delineamento. Mas, tendo já os indícios podemos tratar os dados colhidos ao longo da pesquisa no sentido de direcionar ações, ou na perspectiva de conservar (inutilmente) as relações vigentes, ou de buscar a compreensão do novo, cada vez com mais vigor.

\section{Algumas Considerações Finais}

Seja dito claramente que não pode ser formulado um juízo correto nem sobre o nosso método nem sobre suas descobertas, pelo critério corrente - as antecipações; pois não nos podem pedir acolhimento do juízo cuja própria base está em julgamento

Francis Bacon

O objetivo deste trabalho, já colocado inicialmente, foi o de apresentar os pressupostos teóricos metodológicos que nortearam o desenvolvimento de uma pesquisa sobre a qualidade do atendimento dado a crianças e adolescentes.

Temos claro o risco de que este referencial teórico possa ser confundido, com referenciais já superados que trabalham na linha do "determinismo histórico". Essa confusão poderá decorrer da superficialidade na realização das leituras necessárias a uma apreensão radical do método. A compreensão da atualidade e do caráter inovador do referencial exige um debruçar rigoroso e de longo prazo sobre as fontes clássicas.

Pretendemos com este artigo estabelecer a interlocução com pesquisadores de quem são exigidas respostas e soluções imediatas para determinados problemas e aos quais compete, pelos limites da própria história, somente elucidar, por meio da investigação, a natureza histórica dos objetos estudados.

O que o referencial utilizado no presente artigo não pode, pelo seu caráter histórico, é se 
propor a oferecer modelos e receitas. O que pode é colocar como tarefa possível a busca de uma compreensão mais profunda acerca do emaranhado de forças sociais que produzem o objeto investigado. Entendemos que o mínimo para intervir numa situação é conhecê-la em suas raízes. Caso contrário, corremos o risco de aprofundar as feridas acreditando saná-las.

\section{Referências}

ALVES, Gilberto Luiz. Quatro teses sobre a produção da escola pública contemporânea. Rev. Intermeio, Campo Grande, v. 1, n. 2, p. 6-18, 1995.

ALVES, Gilberto Luiz. As funções da escola pública de educação geral sob o imperialismo. Rev. Novos Rumos, São Paulo, n. 16, p. 89-112, 1990. p. 112).

ANTUNES, Ricardo. Adeus ao trabalho? 3. ed. São Paulo : Cortez; Campinas : Ed. UNICAMP, 1995.

ARRUDA, E.E.; SOUZA, A. A. A.; LIMA, M. F. E. .M.; PEREIRA, S. M.. Sobre(o)viver da criança e do adolescente em Campo Grande/MS. Universidade Federal de Mato Grosso do Sul. Campo Grande /MS, 1996. (EM MIMEO).

ARRUDA, E.E. Trabalho e Escolarização em carvoarias de Mato Grosso do Sul. IN: SENNA, E. Trabalho, Educação e Política Pública. Campo Grande/MS: Editora UFMS, 2003.

BACON, Francis. Novum organum. 3. ed. São Paulo : Abril Cultural, 1984. (Coleção os Pensadores)

HAMMER, Michael; CHAMPY, Jonas. Reengenharia revolucionando a empresa. 28. ed. Rio de Janeiro : Campus, 1994.

LOCKE, John. Segundo tratado sobre o governo. São Paulo : Abril Cultural, 1978. (Coleção os Pensadores).

LUKÁCS, George. Introdução a uma estética marxista: sobre a categoria da particularidade. Tradução: Carlos Nelson Coutinho e Leandro Konder. 2.ed. Rio de Janeiro: Civilização Brasileira, 1978. Coleção Perspectivas do Homem, v.33 - Série Estética.

MARX, Karl; FRIEDERICH, Engels. A ideologia alemã. 6 ed. São Paulo : Hucitec, 1987. p. 23.

REVISTA INOVAÇÃO EMPRESARIAL, São Paulo/SP: ano 4, n. 70, mar. 1996. p.5-6.

TOCQUEVILLE, Alexis de. A democracia na América. Tradução por Neil Ribeiro da Silva. 2 ed., v. 1. Belo Horizonte : Itatiaia; São Paulo : EDUSP, 1977. p. 350-352).

SOUZA, Ana Aparecida Arguelho de. A obra literária e a crise da modernidade. Campo Grande, 2001. (Em mimeo).

A profissionalização do ensino de $2^{\circ}$ grau em MS. Campo Grande, 1994. Dissertação (Mestrado em Educação) - Centro de Ciências Humanas e Sociais, Universidade Federal de Mato Grosso do Sul. p. 23-25.

VOLTAIRE, F.M.A. de. Contos. São Paulo, Abril Cultural, 1979 (Coleção Obras-Primas).

[i] Doutora em Teoria Literária e Literatura Comparada pela UNESP - campus Assis.

Professora da Universidade Estadual de Mato Grosso do Sul ana.arguelho@terra.com.br

[ii] Doutora em Psicologia pela Pontifícia Universidade Católica de São Paulo. Professora 
do Mestrado em Educação da Universidade Federal de Mato Grosso do Sul flarruda@brturbo.com

[iii] Doutora em Engenharia da Produção. Ex- professora da Universidade Federal de Mato Grosso do Sul.

[*] Doutora em Psicologia pela PUC/SP. Prof ${ }^{\mathrm{a}}$ do Departamento de Ciências Humanas e Sociais da UFMS.

[iv] A Pesquisa foi coordenada pela Professora Doutora Elcia Esnarriaga de Arruda e apresentada sob forma de relatório. ARRUDA, E.E. ; SOUZA, A A S. ; LIMA, M. F.E.M.; PEREIRA, S.M. Sobre(o)viver da criança e do adolescente em Campo Grande/MS. Universidade Federal de Mato Grosso do Sul. Campo Grande /MS, 1996. (EM MIMEO). Atendendo a um convite dos editores, as autoras gentilmente cederam o texto para publicação em Trabalho Necessário, tendo o mesmo sido revisado e atualizado pelas autoras em maio de 2006.

[v] MARX, Karl; FRIEDERICH, Engels. A ideologia alemã. 6 ed. São Paulo : Hucitec, 1987. p. 23.

[vi] LOCKE, John. Segundo tratado sobre o governo. São Paulo: Abril Cultural, 1978. (Coleção os Pensadores). p. 31-131.

[vii] Para ilustrar a diferença da natureza dos trabalhos artesanal e manufatureiro e de seus propósitos, tomemos TOCQUEVILLE: Nos séculos aristocráticos, o objetivo das artes é, pois, fazer o melhor possível e não o mais depressa ou a melhor preço. Quando, pelo contrário, cada profissão é aberta a todos, quando a multidão nelas penetra e delas sai sem cessar, e quando os seus diferentes membros se tornam estranhos, indiferentes e quase invisíveis uns aos outros, por causa do seu elevado número, o laço social é destruído e cada trabalhador, entregue a si mesmo, só procura ganhar a maior quantidade de dinheiro possível ao menor custo. [...] Quando apenas os ricos possuiam relógios, estes eram quase sempre excelentes. Agora quase só se os fabricam medíocres mas toda gente os possui. (TOCQUEVILLE, Alexis de. A democracia na América. Tradução por Neil Ribeiro da Silva. 2 ed., v. 1. Belo Horizonte : Itatiaia; São Paulo : EDUSP, 1977. p. 350352).

[viii] Dados acerca do corte de trabalhadores na produção foram apontados nos seguintes trabalhos: ALVES, Gilberto Luiz. Quatro teses sobre a produção da escola pública contemporânea. Rev. Intermeio, Campo Grande, v. 1, n. 2, p. 6-18, 1995.

SOUZA, Ana Aparecida Arguelho de. A profissionalização do ensino de $2^{\circ}$ grau em MS. Campo Grande, 1994. Dissertação (Mestrado em Educação) - Centro de Ciências Humanas e Sociais, Universidade Federal de Mato Grosso do Sul. p. 23-25.

ARRUDA, E.E. Trabalho e escolarização em carvoarias de Mato Grosso do Sul. IN: SENNA,E. (org). Trabalho, Educação e Política Pública. Campo Grande/MS: Editora UFMS, 2003.

[ix] ANTUNES, Ricardo. Adeus ao trabalho? 3. ed. São Paulo : Cortez; Campinas : Ed. UNICAMP, 1995. p. 26.

[x] Clássicas são aquelas obras de literatura, de filosofia, de política, etc., que permaneceram no tempo e continuam sendo buscadas como fontes de conhecimento. $\mathrm{E}$ continuarão desempenhando essa função pelo fato de terem registrado, com riqueza de 
minúcias e muita inspiração, as contradições históricas de seu tempo. (ALVES, Gilberto Luiz. As funções da escola pública de educação geral sob o imperialismo. Rev. Novos Rumos, São Paulo, n. 16, p. 89-112, 1990. p. 112).

[xi] Artigo publicado em revista editada pelo SEBRAE alerta para esse fato: "A OCDE, organização dos sete países mais ricos do mundo, estima em 35 milhões os desempregados nos países desenvolvidos". E prossegue: "para o consultor norteamericano William Bridges, um dos principais anunciadores dessa nova era (escreveu o livro Job Shift, traduzido como 0 mundo sem empregos), essa situação só tende a se acentuar gerando um abalo tão grande na vida das pessoas comparável ao que ocorreu na Revolução Industrial, quando trabalhadores rurais se tranferiram para as cidades. Pessoas que conheciam o trabalho em família tiveram que se submeter a um patrão, a desumanas horas de trabalho, a um salário fixo, o que significou um grande sofrimento", diz, prevendo sofrimentos semelhantes para breve. (REVISTA INOVAÇÃO EMPRESARIAL, ano 4, n. 70, mar. 1996. p. 5-6).

[xii] Essa questão pode ser aprofundada em HAMMER, Michael; CHAMPY, Jonas.

Reengenharia revolucionando a empresa. 28. ed. Rio de Janeiro : Campus, 1994. p. 1 197. Nessa obra os autores recorrem a Adam Smith para evidenciar as diferenças entre o trabalho que marcou a sociedade burguesa em seus primórdios e como este vem mudando a sua dinâmica, no momento atual. Sem nenhuma garantia de que essa mudança represente o novo, podemos fazer uma analogia com o momento em que, por força de necessidades sociais as operações do processo artesanal foram seccionadas e distribuídas a diferentes trabalhadores possibilitando assim a modalidade do trabalho manufatureiro.

[xiii] O esforço da Inquisição enquanto instrumento acionado pela Igreja Católica para a preservação das instituições, relações e valores feudais encontra analogia na proliferação de leis, observada na sociedade atual como um esforço geral, tão inútil como as fogueiras, que mesmo ardendo com vigor não detiveram a marcha da história, porém aparentemente menos violenta.

[xiv] O conceito de qualidade total e a recorrência ao ecletismo e à interdisciplinaridade são alguns dentre os muitos exemplos de produção e perspectiva de conhecimento que não contribuem para as reflexões acerca das necessidades sociais que vêm sendo engendradas pelo movimento dos homens na realização da história e, portanto, para a detecção do "novo", no interior de velhas relações. Também o conhecimento produzido pela filosofia medieval transformou-se em mero exercício escolástico no momento em que novas forças sociais emergiam na história. O grande demolidor iluminista Voltaire (Contos. São Paulo, Abril Cultural, 1979), em Candido ou o otimismo, ironiza aquele pensamento, na figura do filósofo Panglós.

[xv] LOCKE, op. cit.

[xvi] [...] Com o advento da máquina moderna e ao sabor das inovações tecnológicas, a sociedade capitalista passa a produzir imensas quantidades de excedentes; por força das constantes inovações, em contrapartida, grandes contingentes de trabalhadores produtivos são liberados pelas empresas, fazendo crescer o exército industrial de reserva. Esse processo, que tende a se exacerbar gradativamente, contraditoriamente, faz aumentar o número de ociosos e miseráveis. O parasitismo se reflete em especial na evidência de que os ociosos vivem de consumir rendimentos do capital, ou seja, vivem de consumir parcelas de mais-valia. As camadas médias da sociedade capitalista, para efeito de ilustração, correspondem a uma das formas de existência desses ociosos. É muito significativo que, mesmo imediatamente após a Revolução Industrial, mas de forma mais expressiva com o 
advento do imperialismo, essas camadas tenham passado por um processo de ampliação intensivo, cujas características aproximam-no mais da idéia de inchamento.

Sob o imperialismo, portanto, o parasitismo se impõe, assim como a sua reprodução cada vez mais intensa. Contudo, para que esse processo de reprodução funcione sem maiores traumas para o próprio capitalismo, é indispensável controle. Esse controle é assumido pelo Estado, que organiza o parasitismo e transfere, por meio de impostos, parte dos ganhos dos capitalistas para as atividades improdutivas. (ALVES, As funções ..., p.102103)

volta

file://C: Documents and Settings\AdministradorlMeus documentos\Minhas Webs\NED... 4/9/2008 